\title{
Assessment of COVID-19 Vaccine Acceptance and Willingness to Pay by Nigerians
}

\author{
Adamu Mohammed Hassan ${ }^{1,2 *}$, Zubaida Hassan ${ }^{3}$, Husayn Mahmud Muhammad1 \\ ${ }^{1}$ Department of Economics, Federal College of Education, Yola, Nigeria \\ ${ }^{2}$ Department of Planning, Research and Statistics, Adamawa State Primary Health Care Development Agency, Yola, Nigeria \\ ${ }^{3}$ Department of Microbiology, Modibbo Adama University, Yola, Nigeria \\ Email: ^adamuhassan@fceyola.edu.ng, *adoyeyya93@gmail.com
}

How to cite this paper: Hassan, A.M., Hassan, Z. and Muhammad, H.M. (2022) Assessment of COVID-19 Vaccine Acceptance and Willingness to Pay by Nigerians. Health, 14, 137-157.

https://doi.org/10.4236/health.2022.141011

Received: November 10, 2021

Accepted: January 23, 2022

Published: January 26, 2022

Copyright $\odot 2022$ by author(s) and Scientific Research Publishing Inc. This work is licensed under the Creative Commons Attribution International License (CC BY 4.0).

http://creativecommons.org/licenses/by/4.0/

(c) (i) Open Access

\begin{abstract}
Introduction: The COVID-19 Pandemic has affected critical sectors of human development. To curtail these effects, vaccines are being approved for human trials. It is, therefore, important to know the possible vaccine coverage expected in each country. This study determined the willingness of Nigerians to accept and pay for COVID-19 vaccine. Methods: A cross-sectional webbased survey across all states of Nigeria was conducted via a structured equestionnaire. Descriptive statistics, ANOVA and multinomial logistic regression were conducted. Result: A total of 502 responses were obtained from all six geopolitical zones of Nigeria, comprising $67.3 \%$ males $(\mathrm{n}=338)$ and $32.7 \%$ females $(\mathrm{n}=164)$. The results indicated that $34.7 \%(\mathrm{n}=167)$ are willing to accept the vaccine when given for free, $33.9 \%(\mathrm{n}=163)$ are not willing, and up to $31.4 \%(\mathrm{n}=151)$ are indifferent in their decision. Univariate analysis indicated the likelihood that education level could influence willingness to accept the vaccine $(\mathrm{F}=2.408, \mathrm{p}=0.049)$. Rollout strategies may have an impact $(\mathrm{p}<0.0001)$ on the willingness to accept the vaccine. These strategies include providing incentives, making it compulsory and paying for the vaccine with $\mathrm{F}=186.983$ and eta $=0.657, \mathrm{~F}=71.620$ and $\mathrm{Eta}=0.476, \mathrm{~F}=108.696$ and $\mathrm{Eta}=0.552$, respectively. Conclusion: The study revealed a possibility of the low willingness of Nigerians to accept COVID-19 vaccine. Providing incentives is likely to improve coverage, while making the vaccine compulsory may increase rejection. This study, therefore, serves as a gateway for government and policymakers on how best to prime and penetrate the society to achieve massive COVID-19 vaccine coverage in Nigeria.
\end{abstract}

\section{Keywords}

COVID-19 Vaccine, Acceptance, Willingness to Pay, Nigerians 


\section{Introduction}

The outbreak of the novel coronavirus, SARS-CoV-2, declared by the World Health Organisation (WHO) as COVID-19 Pandemic in March 2020 [1], spreads rapidly from country to country, causing what can be regarded as the worst economic calamity experienced globally since the Great Depression of the 1930s. It was first reported in December 2019 in Wuhan, China, as a pneumonialike disease with unknown cause. On January 30, 2020, it was declared by WHO a Public Health Emergency of International Concern (PHEIC) [2] [3]. Coronaviruses are a group of enveloped RNA viruses that often cross species from animals to humans. Before the advent of the SARS-CoV-2, two other coronaviruses outbreaks were recorded in humans [4]. Fortunately, Africa particularly Nigeria was spared of these outbreaks. However, with the current coronavirus, the African region accounted for $\sim 2.97 \%$ of the global incidences as of May 7 , 2021 [5]. Nigeria, being the most populous nation on the continent has reported 165,285 laboratory-confirmed and 2065 death cases as of May 7, 2021 [5] [6].

Nigeria's index case of COVID-19 was reported on February 27, 2020 [7], and since then, the cases continue to rise. The index case was an Italian citizen who entered the country on February 24, 2020, on a Turkish Airlines flight from Milan via Istanbul. There was substantial progress in the efforts of curtailing and containing the spread of the virus. However, with the relaxation of some restrictions to save the economy, among other reasons, a second wave has been observed in the number of new cases in Nigeria [6]. COVID-19 Pandemic has negatively affected virtually all sectors of human development such as health, economy, education and general quality of life, erasing decades of economic progress, poverty reduction, and gains in human development [4] [8]. Furthermore, the negative effects of the COVID-19 Pandemic have negatively changed peoples' lives resulting in the economic recession, unemployment, climate change, technology and the automation of jobs, the rise of digital currencies, lower returns for savings, and rising inequality and debt. All these among others made 2020 a "year like no other" [9].

To cope with living with the virus, the Federal Government of Nigeria has designed and implemented various measures. These include the closure of all educational institutions, closure of airports for both domestic and international flights, a lockdown order for the worst affected states, i.e., Lagos and the FCT, and later, the lockdown order to all parts of the country as enforced by state governments, through a stay-at-home order and restriction in public gatherings. The Nigeria Centre for Disease Control (NCDC) has also increased public awareness through vital communication strategies using electronic, social, and print media to alert Nigerians on the spread of the virus [2]. Importantly, Nigeria is committed and has started to vaccinate its citizens against the SARS-CoV-2. However, there is a growing concern about the readiness of Nigerians to accept the COVID-19 vaccine. Low coverage of COVID-19 vaccines has been reported in many countries. As the vaccine rollout has started in Nigeria, it is important 
to know the possible coverage expected in the country.

There are misconceptions about COVID-19 vaccine, even with the availability of COVID-19 vaccines as demonstrated by the efforts of the Nigerian Government and support from development partners. There are doubts in some quotas about the effectiveness, willingness, and readiness of Nigerians to accept or pay for the COVID-19 vaccines. The decision of Nigerians to accept COVID-19 vaccine could be influenced by the negative conspiracy theories being circulated through various means, including social media platforms. This study, therefore, is conceived to answer the key question: are Nigerians willing to accept and pay for COVID-19 vaccine?

The fact that COVID-19 is an emerging disease, there are not many studies carried out in Nigeria to determine the willingness and readiness of Nigerians to accept and even pay for COVID-19 vaccine. Therefore, the objective of the study is to determine the willingness of Nigerians to accept and pay for the COVID-19 vaccine. The study covers the entire country with responses across all 36 states and federal capital territory, Abuja. The present study would bring additional empirical findings on the readiness of Nigerians to accept COVID-19 vaccines in Nigeria. The results could be useful for future planning and implementation of vaccine-related interventions in the country. The study will also empirically counter the conspiracy theories on COVID-19 Pandemic and its vaccine intervention in Nigeria. The paper is structured as follows; background section, section two presents a review of related literature on COVID-19 vaccines, section three discusses methods including study design, data collection and analysis. Section four presents and discusses the result, and lastly, section five concludes the study with key policy recommendations, ethical approval statement and study limitations.

\section{Related Literature Review}

\subsection{Vaccine and Immunisation Conceptual Framework and Theoretical Linkage}

\section{1) Theoretical framework}

Public health interventions such as vaccine and immunisation services could be linked to the Theory of Change (ToC). This is against the hypothesis that the complexity of public health interventions makes them difficult to be evaluated using traditional experimental designs. Hence public health interventions often rely on continuous quality improvement based on the implementation experience [10]. Despite the increasing popularity of the ToC approach, little is known about the extent to which ToC has been used in the design and evaluation of public health interventions. As such, several researchers proposed that understanding the public health interventions using ToC and its related uncertainties may improve the evaluation of complex health interventions [10] [11] [12] [13].

\section{2) Conceptual framework}

The $\mathrm{ToC}$ was adopted from the framework developed by Mookherji and La- 


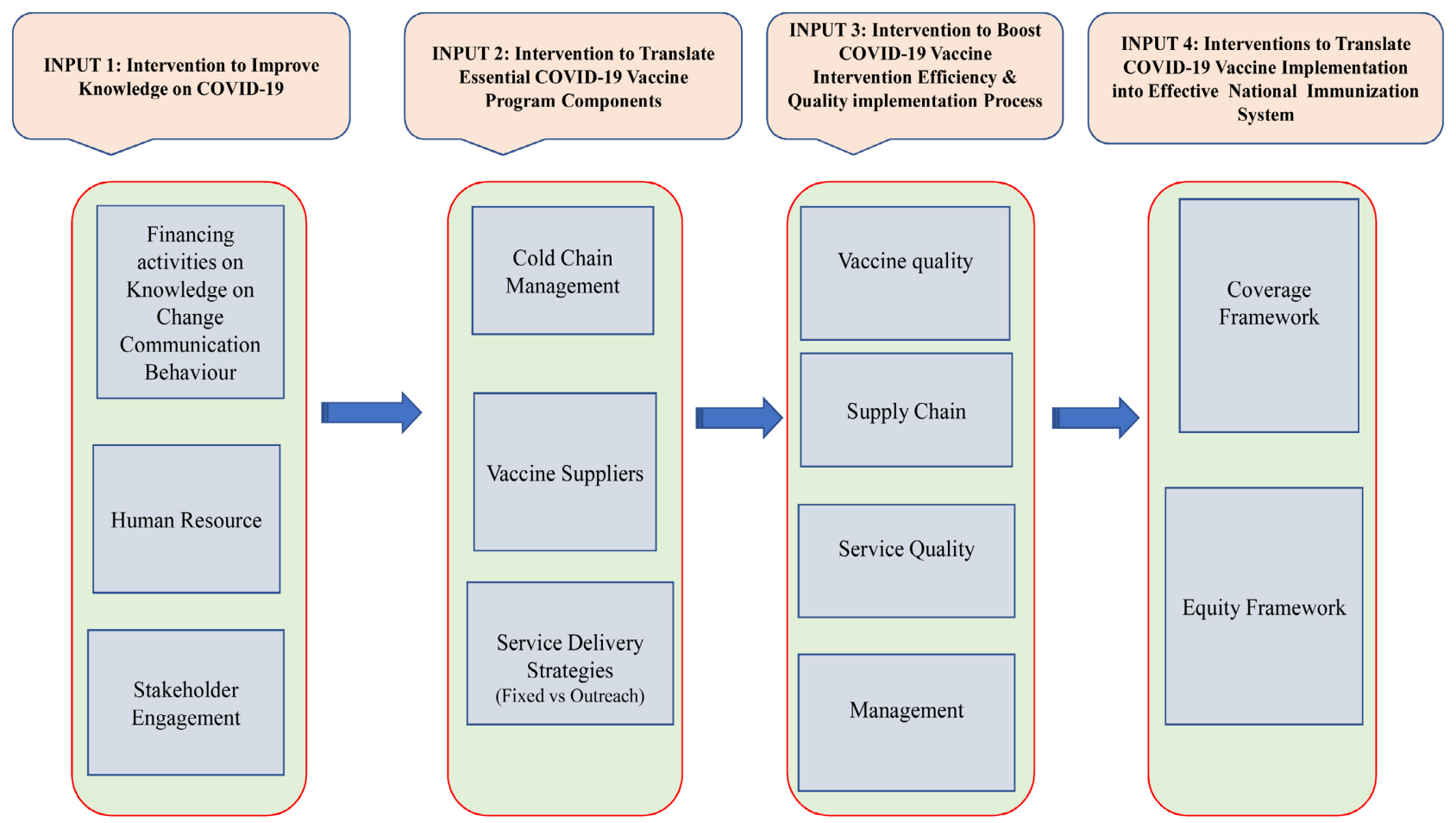

Figure 1. Conceptual framework for a successful rollout of COVID-19 vaccine. Source: Researcher design adapted from Mookherji and LaFond [14]. 


\subsection{Government Response to COVID-19}

The Government of Nigeria has intensified efforts in creating awareness on the mode of transmission of SARS-CoV-2, the causative agent of COVID-19. The means of transmission of this virus include direct contact with surfaces contaminated by the virus and inhalation of contaminated air [15]. Therefore, regular hand hygiene and wearing facemask/shield had been advocated. Aside from the non-pharmaceutical interventions (NPIs) such as isolation/quarantine, physical distancing, use of facemasks and hand hygiene, COVID-19 vaccines are being administered in several countries as part of the global effort to curb the spread of the disease. Nigeria and the world at large are working toward a sustainable response mechanism. WHO and partners are working together on the response-tracking of the Pandemic, critical interventions, including distributing vital medical supplies to the needy. Other sustainable response-tracking mechanisms are, developing and deploying safe and effective COVID-19 vaccines, WHO [1].

Arguably, vaccines save millions of lives each year, and vaccines through immunisation are one of the most cost-effective public health interventions [16]. WHO and partners such as Gavi and UNICEF ensure the availability of the needed infrastructure and technical support for the successful delivery of the COVID-19 vaccines [17]. There are currently several COVID-19 vaccine candidates approved by WHO (Figure 2). In many countries, the vaccines are being administered most often, on a voluntary basis. The National Primary Health Care Development Agency (NPHCDA) is leading the Nigeria's efforts to access safe, effective, and efficacious COVID-19 vaccine. Thus, only the vaccines approved by the Government of Nigeria and provided through accredited means should be accessed [6].

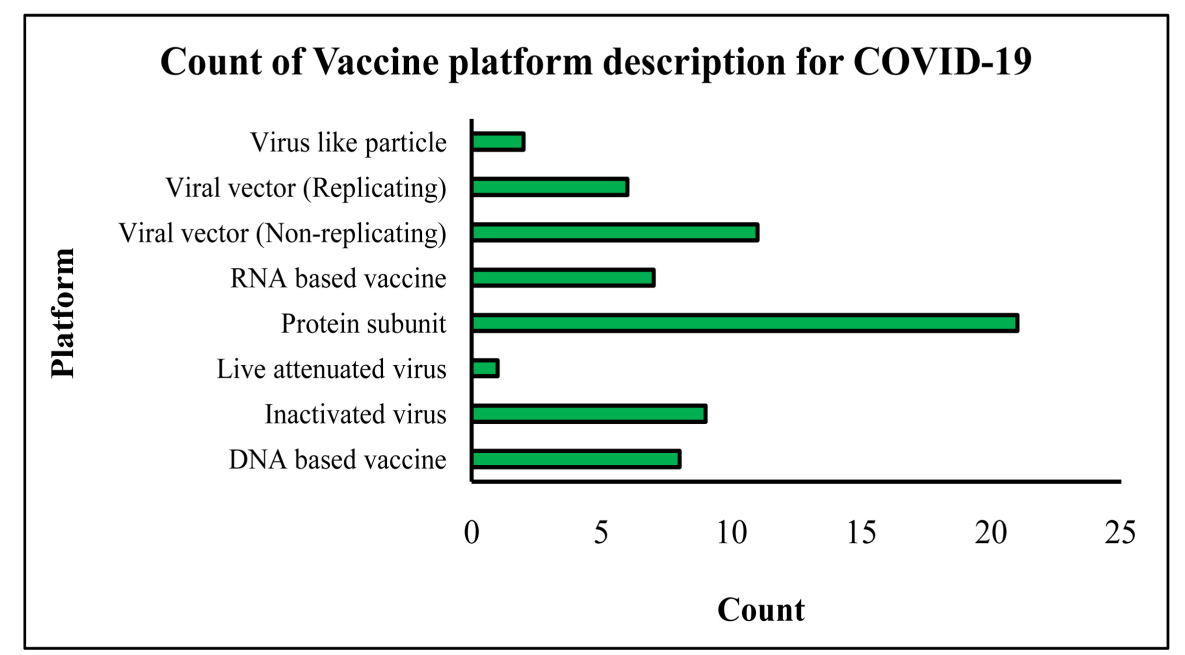

Figure 2. Number of platforms used in the production of COVID-19 vaccines that are in clinical trials. There are 63 COVID-19 vaccines that are in clinical trials. Out of these, 22 are in phase 3 trials, which include the inactivated virus and non-replicating viral vectored-based candidates. Source: [17]. 


\subsection{Some Concerns on COVID-19 Vaccine in Nigeria}

As the world starts the rollout of COVID-19 vaccine, the WHO is concerned about the catastrophic moral failure (vaccine nationalism) in sharing the vaccines [18]. Vaccine nationalism may often leave the world's poorest and most vulnerable at risk and, in turn, prolong the Pandemic [18]. Similarly, the poor and vulnerable Nigerians are of concern in the vaccine rollout; therefore, careful preparation is crucial.

\section{1) Preparation for the vaccine}

Since COVID-19 vaccine is needed for herd immunity against the virus, it must reach the entire population. To achieve the desired goal, certain steps must be followed. Here, we outlined these steps to include priming the community and preparing healthcare workers. We appreciate the existing immunisation structure on the ground could serve in the delivery of COVID-19 vaccine as well. However, the government must take note of the community side. Therefore, we will focus on the aspect of community priming for successful mass vaccination.

2) Priming the community

\section{a) Creating awareness}

A substantial number of people in communities are not aware of how vaccines work nor the stringent steps involved in their development. This makes people believe whatever negative information that comes their way on vaccination. The majority of individuals in society know COVID-19; hence, awareness of its vaccine is of paramount importance. Public awareness has been shown to be very effective in any public health intervention [19] [20]. Social and mass media platforms such as WhatsApp, Facebook, radios and televisions could be very useful in this campaign.

\section{b) Developing confidence in COVID-19 vaccine}

Access to information is very easy in recent times, especially through social media. Unfortunately, most people do not verify the authenticity of such information. A lot of negative information on COVID-19 and, in particular, the vaccines have been circulating in Nigeria. General concerns have been raised about these vaccines and the fact that they have not been locally developed. Therefore, it is important for the Government to relate to the community on how the authenticity of these vaccines is ascertained locally, together with open administration of the vaccines to top officials and public figures, among other measures.

c) Giving incentives

In addition to free administration of the vaccines in society, giving incentives for those vaccinated may go a long way in improving the coverage. For example, to improve COVID-19 vaccine coverage, the USA and UAE had offered different degrees of incentives for vaccinated populations [21] [22]. Similarly, a mobile incentive approach has been shown to improve child immunisation in India [23].

d) Making COVID-19 vaccine mandatory

Institutions and organisations may need to be involved in verifying the au- 
thenticity of the vaccines, and they may be given the mandate to make it mandatory for anyone accessing their facilities. In certain instances, employers can make vaccinations mandatory for their employees [24] [25] [26].

\section{e) Law enforcement}

If all the aforementioned are well in place, it would be a good idea for both Governments and institutions to enforce penalties for any violator of the COVID19 vaccine regulations [26].

\subsection{Lessons from Other Countries on COVID-19 Vaccine}

Economically advanced countries such as Italy, the USA and the UK, which have been reported to have the highest burden of infection and deaths from COVID19 [27], have since started administering the COVID-19 vaccine to their citizens [28] [29] [30]. Nearly 40 million doses of the COVID-19 vaccine had been administered in 49 higher-income countries as at January 18, 2021 [18]. The strategy adopted in the rollout of COVID-19 vaccine in many countries is impressive. For example, in the USA, Louisiana State redeploys the vaccine based on the vulnerability index and utilises retail pharmacies in its distribution [31]. In Israel, a deal on "give us vaccine, we'll give you the national data on the vaccine efficacy" was struck on an early supply of Pfizer-BioNTech vaccine [32]. This would be a very good approach if Nigeria will adopt. Nigeria is a very big multicultural and the most populous nation in Africa. It can generate data not only on vaccine efficacy but also its effects on the African race. There have been many doubts as to why the African continent is spared of the previous coronaviruses and hit below predictions with the current coronavirus, SARS-CoV-2 [4]. Another important strategy is the "use of a low dead-weight syringe in the administration of the COVID-19 vaccine". This will help increase the number of doses and subsequently increase coverage at a relatively the same cost. The low deadweight syringe is known to provide an additional one or even two doses of vaccine per vial [30].

\subsection{Advances and Approaches in Vaccine Technology Viz-A-Viz COVID-19 Vaccine}

Vaccinology, a science of vaccine development, encompasses many fields of studies, including basic life sciences such as molecular/microbiology and immunology, manufacturing, technologies, clinical evaluation, safety regulations, and ethical issues [33]. Vaccines are the most effective public health intervention programmes in reducing morbidity and mortality due to infectious diseases [34], which COVID-19 falls into. To date, there are $\sim 50$ licensed human vaccines; however, none of them is $100 \%$ effective nor $100 \%$ safe [33]. Nonetheless, vaccination programmes save about 2 - 3 million lives globally each year [35] [36].

Advances in the field of molecular biology and documented knowledge on previously identified pathogens coupled with collaborative efforts of funders, developers and regulators have greatly improved and facilitated the process of vac- 
cine development [33]. For instance, the first Ebola virus vaccine, rVSV-EBOV, was approved for human use within a 14 months period from the identification of the virus [37] [38]. Although, full license of Ebola vaccine happens in 2019 when the outbreak is over [39]. It is not surprising that the COVID-19 vaccine is approved for human use within a shorter period. This is because there are $\sim 5$ years of advancement since the Ebola outbreak, documented information on SARS-CoV-1, the closest counterpart of COVID-19 virus, SARS-CoV-2, and of course, being a pandemic; it attracts more funders, developers and regulators. For example, the COVID-19 vaccine from Pfizer-BioNTech was administered to health workers in the UK and the USA on December 10, 2020, exactly 11 months after the SARS-CoV-2 was sequenced [30].

There are several modes of vaccine developments out of which six methods have been majorly employed for COVID-19 production (Figure 2), these are; inactivated virus, recombinant viral vectored, protein subunit, live attenuated virus, virus-like particles and nucleic acid-based [17] [39] [40]. As of January 26, 2021, there are a total of 237 COVID-19 vaccine candidates, with 174 in preclinical trials and 63 already in clinical trials [17]. Top on the list of candidates in clinical trials is mainly inactivated virus and non-replicating viral vectored-based candidates with 2 booster doses [17].

\section{Methods}

\subsection{Study Design and Sample}

This is a cross-sectional web-based study across all the 36 states of Nigeria and the Federal Capital Territory, Abuja. The questionnaire was developed based on a review of related literature. The content validity of the questionnaire was confirmed by a panel of experts. The clarity of the questionnaire was validated in a pilot study of about 30 participants from several states of Nigeria. In both validation methods, minor modifications were made. The final version of the questionnaire contains 30 questions with three sections. In this study, we included and analysed a total of 19 questions from two sections obtained using the structured e-questionnaire (see questionnaire attached in the supplementary section). The two main sections of the questionnaire for this study are Section A: demographic characteristics, including gender, age, nationality, country of residence, state of origin, marital status, education level, and occupation. Section B: awareness and willingness of Nigerians to accept and pay for COVID-19 vaccination. For section B questions, the participants were asked to select an option from either Yes/No or Yes/No/Don't know. Two categories of questions from section B pertaining to COVID-19 vaccine uptake and utilisation in Nigeria were the principal target for the study. These questions are: is the respondent voluntary willing to accept the COVID-19 vaccine? And what impact does strategic rollout has on willingness to accept the COVID-19 vaccine? The strategic rollout includes "if the vaccine is given for free", "if the government provides some incentives for accepting the vaccine", "if the government makes the vaccine com- 
pulsory" and "willingness to pay as out of pocket for the vaccine if not given for free".

\subsection{Study Participants}

A total of 502 participants from the 36 States of Nigeria and Federal Capital Territory, Abuja participated voluntarily in the survey. Participants were recruited to the study via a variety of methods, including online, telephone and direct message solicitation, and social media platforms, such as WhatsApp, Facebook, Twitter, and Instagram. The study inclusively considered only responses from Nigerians residing in the country at the time of the data collection as the target population of the study and excluded responses from Nigerians outside the country. This information is obtained from the response to one of the demographic questions: "country of residence". This criterion of including only Nigerians residing in the country at the time of this survey is important because the vaccine rollout is a concern primarily to the residence.

\subsection{Data Collection}

Survey data were collected from January 15 to March 3, 2021, using google forms online panel. The e-questionnaire containing both open and close-ended questions was designed and distributed via online platforms. Participation in this survey was made totally voluntary. Electronic informed consent was obtained before enrolling on the study. At the end of the data collection period, the available data were downloaded from the online google document into a Microsoft Excel file, cleaned, and formatted accordingly.

\subsection{Statistical Analyses}

Statistical data analysis was conducted using SPSS version 26. Descriptive analysis was done to obtain percentage responses in each variable. Bivariate analysis performed included correlation analysis of demographic factors to "willingness to accept COVID-19 vaccine if given for free" as obtained from the six geopolitical zones of Nigeria. Multinomial logistic regression model was used to evaluate the predictive effect of demographic data and rollout strategies on respondents' willingness to accept COVID-19 vaccine. We first fit the data on demography and rollout strategies with the outcome variable, that is "willingness to accept COVID-19 vaccine if given for free" in two separate models. Variables that were significantly associated with the outcome variable at $p<0.05$ were included in the model. Pearson's chi-square correlation coefficient $(p>0.05)$ was used to eliminate variables that are highly correlated, to ensure that the model is fit for the multinomial logistic regression analysis. Loglikelihood ratio tests were also used to evaluate the predictive performance of each covariate. Two-way interaction terms of the variables in the final main effects model were then assessed for statistical significance and their $95 \%$ confidence intervals (CI). Minimal missing data were recorded in the data set. 


\section{Results}

\subsection{Descriptive Statistics}

This study was conducted from 502 responses obtained from Nigerians residing in the country at the time of this survey. These responses were from all six geopolitical zones. There were $67.3 \%$ males $(n=338)$ and $32.7 \%$ females $(n=164)$. About $93.2 \%(n=468)$ of the respondents have above secondary school level of education (classified as "tertiary level" in this study), while $4.4 \%(\mathrm{n}=22)$ have secondary school level of education. $2.2 \%(n=12)$ had missing data on education level. We recoded the raw data received on age into three categories (under $18,18-65$ and above 65 years) to conform to the age approved for receiving COVID-19 vaccine [41], and to assess the willingness to accept COVID-19 vaccine among the "priority targets", that is above 65 years [42]. However, we did not record any data from the elderly (aged above 65 years). A $95.8 \%(n=481)$ of the respondents were within the 18 - 65 years range cluster, $1.8 \%(n=9)$ are under 18 , and we had $2.2 \%(\mathrm{n}=12)$ had missing data. Table 1 indicates that there was not much difference in the rate of acceptance $(34.7 \%, \mathrm{n}=167)$ and rejection $(33.9 \%, \mathrm{n}=163)$ to COVID-19 vaccine if given for free. However, there was a

Table 1. Descriptive statistics on demographic distribution of respondents.

\begin{tabular}{|c|c|c|c|}
\hline \multicolumn{2}{|c|}{ Variable } & \multirow{2}{*}{$\begin{array}{c}\text { Number } \\
167\end{array}$} & \multirow{2}{*}{$\begin{array}{c}\text { Percentage (\%) } \\
34.7\end{array}$} \\
\hline Will you take & Yes & & \\
\hline \multirow{2}{*}{$\begin{array}{l}\text { COVID-19 vaccine if } \\
\text { given for free? }\end{array}$} & No & 163 & 33.9 \\
\hline & Maybe & 151 & 31.4 \\
\hline \multirow{3}{*}{$\begin{array}{c}\text { Do you think } \\
\text { COVID-19 vaccine is } \\
\text { safe? }\end{array}$} & Yes & 133 & 26.5 \\
\hline & No & 108 & 21.5 \\
\hline & Maybe & 255 & 50.8 \\
\hline \multirow{2}{*}{ Age range (years) } & Under 18 & 9 & 1.9 \\
\hline & $18-65$ & 472 & 98.1 \\
\hline \multirow{6}{*}{ Geopolitical zone } & North-Central & 48 & 10.0 \\
\hline & North-East & 250 & 52.0 \\
\hline & North-West & 98 & 20.4 \\
\hline & South-East & 10 & 2.1 \\
\hline & South-South & 6 & 1.2 \\
\hline & South-West & 69 & 14.3 \\
\hline \multirow{3}{*}{ Level of Education } & Tertiary & 446 & 93.2 \\
\hline & Secondary & 21 & 4.4 \\
\hline & Missing & 10 & 2.1 \\
\hline \multirow{2}{*}{ Gender } & Female & 158 & 32.8 \\
\hline & Male & 323 & 67.2 \\
\hline
\end{tabular}


large indecisive percentage. Similarly, more than $50 \%(n=225)$ of the responders are indecisive in the safety of the vaccine, while more than $20 \%(\mathrm{n}=108)$ of the respondents think it is not safe.

The responses recorded vary considerably across the geopolitical zones, for example, the least responses obtained were obtained from the South-South zone, with only six respondents, while the highest was obtained from the North-Eastern zone with 250 respondents. Therefore, we mapped the rate of acceptance/ rejection as the percentage response obtained in each zone (Figure 3 and Figure 4). Thus, the survey revealed that the region with the highest possible acceptance rate is the South-South, with $50.0 \%$ responses willing to accept COVID-19 vaccine. This is followed by a $38.8 \%$ acceptance rate from the North-East and North-Central Nigeria (Figure 3). This could be because the South-South region has only six responses. The data indicate a possible significant level of vaccine hesitancy among the masses in Nigeria prior to the kick-start of the vaccine (Figure 4).

Having observed a high tendency of COVID-19 vaccine rejection in the country, we modelled the association using a multinomial logistic regression model to understand how certain strategies, including giving incentives and making the vaccine compulsory predict the willingness to accept the vaccine. Prior to this, we analysed the perception of respondents' willingness to pay for the vaccine if not given for free. All three variables were significantly associated with the willingness to take the vaccine $(p<0.0001)$. However, the data implied that making the vaccine compulsory or paying for it may likely increase the rejection rate (Table 2).

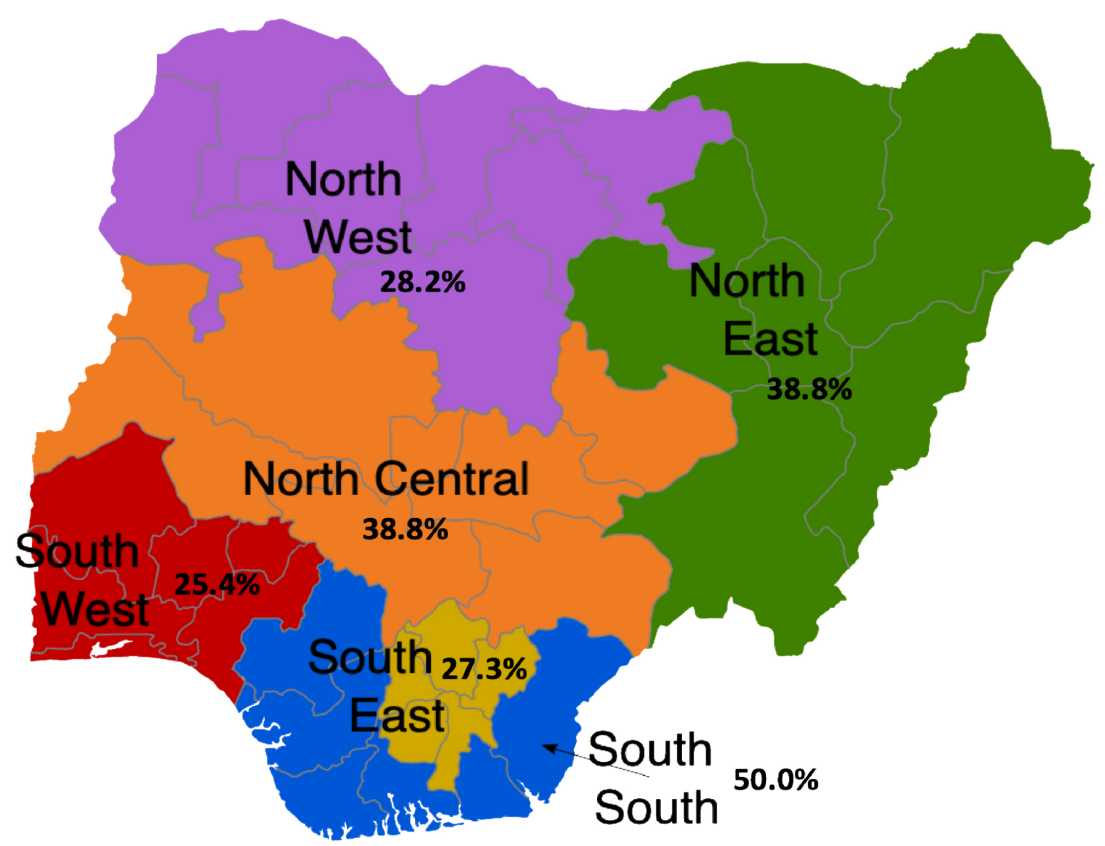

Figure 3. Geopolitical distribution of the rate of acceptance of COVID-19 in Nigeria. The acceptance rate of COVID-19 vaccine distribution in the country across all the geopolitical zones is below average. 


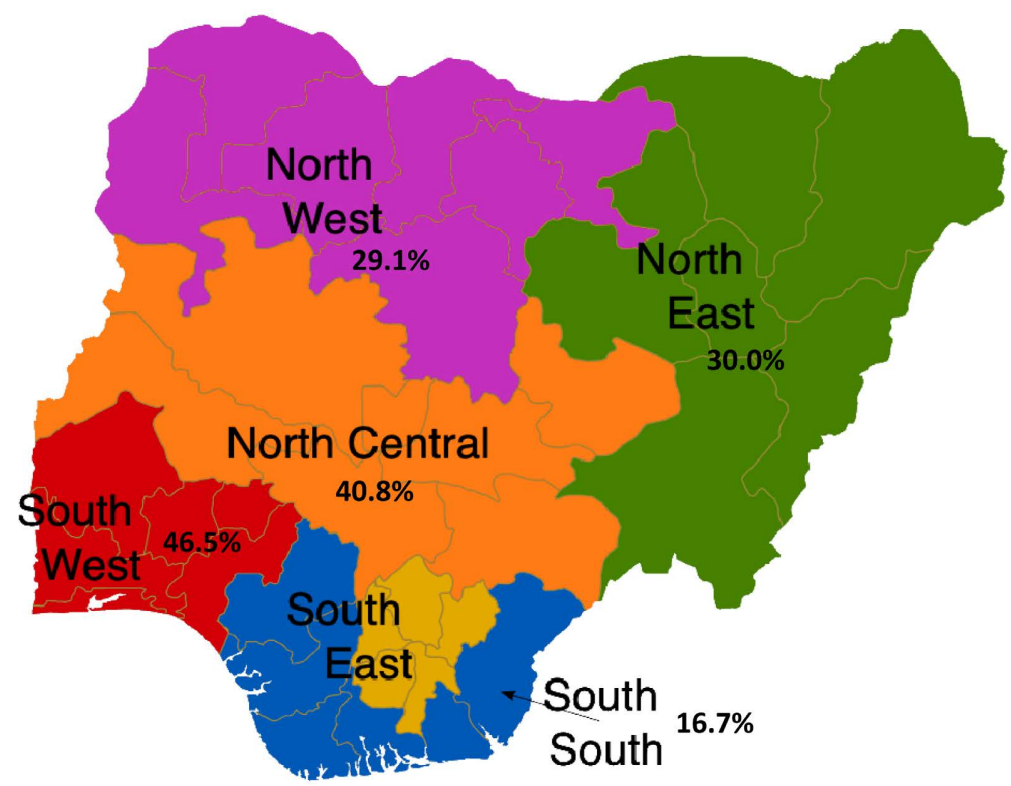

Figure 4. Geopolitical distribution of the rate of rejection of COVID-19 in Nigeria. The rejection rate of COVID-19 vaccine in Nigeria is high, although it is below $50 \%$ across all the geopolitical zones.

Table 2. Impact of rollout strategies on willingness to accept COVID-19 vaccine.

\begin{tabular}{cccc}
\hline Strategy & & Number & Percentage \\
\hline Willingness to accept COVID-19 & Yes & 172 & 34.7 \\
vaccine if given for free & No & 167 & 33.9 \\
\hline Willingness to accept COVID-19 & Maybe & 152 & 31.4 \\
vaccine if government provides & Yes & 169 & 34.4 \\
some incentives & No & 177 & 36.0 \\
\hline Willingness to accept COVID-19 & Maybe & 145 & 29.5 \\
vaccine if government makes it & Yes & 116 & 23.6 \\
compulsory. & No & 212 & 43.2 \\
\hline Willingness to pay for COVID-19 & Maybe & 163 & 33.2 \\
vaccine if not given free. & Yes & 117 & 23.8 \\
& No & 251 & 51.1 \\
& Maybe & 123 & 25.1 \\
\hline
\end{tabular}

\subsection{Univariate Association}

We performed ANOVA to assess if there is any direct association of the variables on willingness to accept COVID-19 vaccine. Our data indicated that level of education could have a potential effect $(\mathrm{F}=2.408, \mathrm{p}=0.049)$ with an Eta value of 0.138 . None of the other demographic variables resulted in a significant association (Table 3). Rollout strategies (incentives, compulsion, and payment) on the other hand, all resulted in significant associations with $p<0.0001, \mathrm{~F}=186.983$ and eta $=0.657, \mathrm{~F}=71.620$ and $\mathrm{Eta}=0.476, \mathrm{~F}=108.696$ and $\mathrm{Eta}=0.552$, respectively (Table 3 ). 
Table 3. Association of key variables on willingness to accept COVID-19 vaccine.

\begin{tabular}{cccc}
\hline S/N & Variable & F-value $(p$-value $)$ & Eta-value \\
\hline 1. & Age & $1.283(0.258)$ & 0.051 \\
2. & Gender & $0.476(0.491)$ & 0.031 \\
3. & Education level & $2.408(0.049)$ & 0.138 \\
4. & Geopolitical region & $0.835(0.525)$ & 0.093 \\
5. & Incentives & $186.983(<0.0001)$ & 0.657 \\
6. & Compulsion & $71.620(<0.0001)$ & 0.476 \\
7. & Payment & $108.696(<0.0001)$ & 0.552 \\
\hline
\end{tabular}

\subsection{Multivariate: Multinomial Logistic Regression Model Analysis}

Multinomial logistic regression model was used to model how demographic data such as age range, gender, education level and geopolitical region predict respondents' willingness to accept COVID-19 vaccine. A statistically significant association was observed only with the age range $(p=0.035)$ (Table 4$)$. The skewness of age to a single range (18 - 65 years) could be a contributing factor to this association. However, the overall model indicated that demographic parameters are not likely to have an influence on willingness to accept the COVID-19 vaccine in Nigeria $(0.210, p=0.527)$.

Contrary to the demographic impact, rollout strategies significantly influence the acceptance of COVID-19 vaccine in Nigeria. The multinomial regression model indicates that the combined effect of providing incentive and making the vaccine compulsory would likely increase rejection significantly, $(1.240, \mathrm{p}=0.17$, $95 \% \mathrm{CI}=1.243-9.604)$ and $(2.277, \mathrm{p} \leq 0.0001,95 \% \mathrm{CI}=3.982-23.869)$, respectively. Payment on the other hand may slightly but significantly decrease rejection $(-0.332, p \leq 0.0001,95 \% \mathrm{CI}=3.524-24.053)$.

Table 4. Impact of demographic data on willingness to accept COVID-19 vaccine.

\begin{tabular}{cccc}
\hline S/N & Variable & Likelihood ratio $(\mathrm{df})$ & $p$-value \\
\hline 1. & Age range & $6.722(2)$ & 0.035 \\
2. & Gender & $2.891(2)$ & 0.236 \\
3. & Education level & $8.383(8)$ & 0.397 \\
4. & Geographical region & $7.200(10)$ & 0.706 \\
\hline
\end{tabular}

\section{Discussion}

Second wave of COVID-19 hit countries globally as a result of relaxation in various preventive measures such as ease of restrictions, lockdown measures, as well as reopening of public places. Similarly, the COVID-19 cases began to rise in Nigeria. During the second wave of the virus, Nigeria has recorded the highest case per day of 2314 on January 22, 21 [6]. To curb the surge of the virus and to prevent possible third wave, vaccine remains the viable alternative. Many coun- 
tries, including the USA, have authorised the use of COVID-19 vaccines. Vaccination is one of the most cost-effective public health interventions globally [16]. Vaccines work by helping individuals develop immunity to a pathogen, for example, SARS-CoV-2, in the case of COVID-19. This happens by stimulating the immune system to produce antibodies that could target and neutralise the infection, and thus, keep the person from developing symptoms or at least reduce the severity of the sickness.

Surveys from different countries, including Nigeria, revealed that strong public hesitancy to the COVID-19 vaccine is growing [43]. In Nigeria, public hesitancy to COVID-19 vaccine is apparently a major obstacle to achieving significant coverage of the vaccine. Our data indicate that only about $35 \%$ of Nigerians are willing to accept the vaccine across the six geopolitical zones of the country. This result is consistent with the findings from several surveys where for example, only $26.4 \%$ of the Middle-East population and $27.3 \%$ of respondents from Poland were willing to accept COVID-19 vaccines [43] [44]. The acceptance rate of $35 \%$ obtained in this study is below the threshold required for herd immunity [43]. While the vaccination coverage required to achieve herd immunity against COVID-19 is yet to be confirmed, $80 \%$ and $95 \%$ coverage is needed for other viral infections such as polio and measles, respectively [45]. Barely 40 days of the commencement of COVID-19 vaccination in Nigeria, from April 1 to May 6, 2021, a total of 1,289,773 clients were vaccinated in Nigeria. This represents $64.1 \%$ as a proportion of people vaccinated from the targeted Nigerians in phase 1 of the vaccination [46]. The coverage of $64.1 \%$ was from the available four million doses of Oxford/AstraZeneca vaccine obtained in Nigeria for the first phase of the vaccination rollout. The geopolitical zones distribution of this indicated that North-East had 51.1\%, North-West with $40.5 \%$ and North-Central recorded $44.8 \%$ coverage. Others are South-East with $21.8 \%$, and each of South-West and South-South recorded $67.1 \%$ and $33.0 \%$ coverage, respectively.

Another growing concern to the willingness to accept the COVID-19 vaccine in Nigeria observed in this study is the impact of the strategic rollout. For example, we observed a decrease in acceptance rate from $34.7 \%$ to $23.6 \%$ and $23.8 \%$ if government makes the vaccine compulsory and if people would pay for it, respectively. In our data set, we observed that making the COVID-19 vaccine compulsory in Nigeria is likely to decrease the acceptance rate among masses by up to $32 \%$ and, in turn, increase the rejection rate from $33.9 \%$ to $43.2 \%$. The opinion as to whether COVID-19 vaccine should be made mandatory is extensively discussed by McMillan [47]. Countries have varying views on this matter, for example, Brazil is in favour of making COVID-19 vaccine mandatory, whereas countries such as Australia do not support it [47]. In a study of 193 countries, more than 100 countries have some kind of nationwide mandatory vaccination policy [48]. Some even impose financial or educational (refusing school enrolment) penalties for non-compliance [48]. Similarly, in Nigeria, a complete childimmunisation card is required for school enrolment. 
In the present times, Nigeria has made COVID-19 vaccine mandatory for frontline health workers and international travellers. Similarly, the Kingdom of Saudi Arabia government has announced that all pilgrims entering the kingdom for hajj shall be vaccinated against COVID-19, in addition to negative PCR test results [49] [50]. These could be contributing factors for the significant increase in the coverage (64.1\%) reported for COVID-19 vaccine in the first phase in $\mathrm{Ni}$ geria [46], which is higher than our findings of only $34.7 \%$ of Nigerians are willing to accept the vaccine.

An important factor contributing to the low level of COVID-19 vaccine acceptance observed in this study could be the safety concern. Lack of confidence in the safety of the COVID-19 vaccine is a possible cause of hesitation or refusal of the vaccine reported from many countries across Asia, America, and Europe [44] [51] [52] [53]. Amidst this hesitancy reports on COVID-19 vaccine from various studies, there are speculations and growing concerns of the general safety of the only vaccine supplied to Nigerians, Oxford/AstraZeneca, during the time of this report. There are reports linking this vaccine to blood clots [54] [55]. However, at present, this problem is studied, and thus listed as a very rare side effect of the Oxford/AstraZeneca vaccine [55] [56]. The use of this vaccine has been given interim recommendation [57]. Other side effects of the Oxford/ AstraZeneca vaccine include pains or tenderness at the injection site, headache, tiredness, muscle or joint aches, fever, chills, and nausea.

With the increase instances of COVID-19 vaccine hesitation and rejections, asking people to pay out-of-pocket to be vaccinated will only worsen the situation, and in turn, affect the overall coverage. Not surprising, however, our data revealed that COVID-19 rejection rate is likely to increase from $33.9 \%$ to $51.1 \%$ if people were to pay as out-of-pocket. Nonetheless, about $23.8 \%$ of our respondents are ready to do so. It is possible that Nigeria and perhaps many other African countries would find it difficult to finance the COVID-19 vaccine program; this could lead to poor coverage which in turn may prolong the Pandemic. To mitigate this situation, the World Bank has approved $\$ 12$ billion funds to aid the developing countries in acquiring vaccines projected to reach a billion people [58] [59].

\section{Conclusion}

As COVID-19 vaccines are being approved for human trials, countries around the world are ensuring safe and effective vaccines are administered to their citizens to attain herd immunity to the virus, SARS-CoV-2. As in many countries, Nigeria's public survey data presented in this study revealed a possibility of low willingness to accept the vaccine. Providing incentives to those vaccinated is likely to improve the vaccine coverage, while making it compulsory or pay outof-pocket may increase rejection. This study, therefore, serves as a gateway for government and policymakers on how best to prime and penetrate the society for massive COVID-19 vaccine coverage in Nigeria. 


\section{Limitation}

It must be noted that all public surveys particularly the type reported here are mare snapshots taken at a point in time. This survey was conducted at a time when there were consistent variations in COVID-19 cases across states, with daily variations in perceived pandemic threat through mutations of the virus and vaccine development process and evolution.

\section{Ethics Statement}

The studies involving human participants were reviewed and approved by the Adamawa State Ministry of Health Yola, Nigeria, with reference number: ADHREC 05/04/2021/049. The participants provided their informed consent to participate in this study by clicking the 'accept to participate' button in the questionnaire consent sub-section.

\section{Authors' Contributions}

Adamu Mohammed Hassan conceived the study, designed the conceptual framework, collected the data, identified, and presents the study design, performed discussion, edited, and approved the final manuscript. Zubaida Hassan discussed the vaccine-related literature, collected the data, analysed the data and presented the results, as well as edited and approved the final manuscript. Husayn Mahmud Muhammad collected the data, participated in data cleaning and choice of statistics, read, and approved the final manuscript.

\section{Competing Interests}

The authors wish to report and disclaim any form of claim of authorship from anyone.

\section{References}

[1] WHO (2020) Timeline: WHO’s COVID-19 Response. https://www.who.int/emergencies/diseases/novel-coronavirus-2019/interactive-time line

[2] Nnama-Okechukwu, C.U., Chukwu, N.E. and Nkechukwu, C.N. (2020) COVID-19 in Nigeria: Knowledge and Compliance with Preventive Measures. Social Work in Public Health, 35, 590-602. https://doi.org/10.1080/19371918.2020.1806985

[3] Zhu, N., et al. (2020) A Novel Coronavirus from Patients with Pneumonia in China, 2019. New England Journal of Medicine, 382, 727-733. https://doi.org/10.1056/NEJMoa2001017

[4] Hassan, Z., Hashim, M.J. and Khan, G. (2020) Population Risk Factors for COVID19 Deaths in Nigeria at Sub-National Level. The Pan African Medical Journal, 35, Article No. 131

[5] Worldometer (2021) Coronavirus Update (Live): 99,520,105 Cases and 2,134,070 Deaths from COVID-19 Virus Pandemic. https://www.worldometers.info/coronavirus/\#countries

[6] NCDC (2021) NCDC Coronavirus COVID-19 Microsite. https://covid19.ncdc.gov.ng/ 
[7] NCDC (2020) Nigeria Centre for Disease Control. https://ncdc.gov.ng/

[8] World Bank (2020) Annual Report 2020.

https://www.worldbank.org/en/about/annual-report

[9] IMF (2020) IMF Annual Report 2020: A Year Like No Other. https://www.imf.org/external/pubs/ft/ar/2020/eng/

[10] Breuer, E., Lee, L., De Silva, M. and Lund, C. (2016) Using Theory of Change to Design and Evaluate Public Health Interventions: A Systematic Review. Implementation Science, 11, Article No. 63. https://doi.org/10.1186/s13012-016-0422-6

[11] De Silva, M.J., et al. (2014) Theory of Change: A Theory-Driven Approach to Enhance the Medical Research Council's Framework for Complex Interventions. Trials, 15, Article No. 267. https://doi.org/10.1186/1745-6215-15-267

[12] Ling, T. (2012) Evaluating Complex and Unfolding Interventions in Real Time. Evaluation, 18, 79-91. https://doi.org/10.1177/1356389011429629

[13] Mackenzie, M., O’Donnell, C., Halliday, E., Sridharan, S. and Platt, S. (2010) Do Health Improvement Programmes Fit with MRC Guidance on Evaluating Complex Interventions? British Medical Journal, 340, c185. https://doi.org/10.1136/bmj.c185

[14] Mookherji, S. and LaFond, A. (2013) Strategies to Maximize Generalization from Multiple Case Studies: Lessons from the Africa Routine Immunization System Essentials (ARISE) Project. Evaluation, 19, 284-303.

https://doi.org/10.1177/1356389013495212

[15] Ningthoujam, R. (2020) COVID 19 Can Spread through Breathing, Talking, Study Estimates. Current Medicine Research and Practice, 10, 132-133. https://doi.org/10.1016/j.cmrp.2020.05.003

[16] Feikin, D.R., Flannery, B., Hamel, M.J., Stack, M. and Hansen, P.M. (2016) Vaccines for Children in Low- and Middle-Income Countries. In: Black, R.E., Laxminarayan, R., Temmerman, M. and Walker, N., Eds., Reproductive, Maternal, Newborn, and Child Health: Disease Control Priorities, The International Bank for Reconstruction and Development/The World Bank, Washington DC, 187-204. https://doi.org/10.1596/978-1-4648-0348-2 ch10

[17] WHO (2021) Draft Landscape and Tracker of COVID-19 Candidate Vaccines. https://www.who.int/publications/m/item/draft-landscape-of-covid-19-candidate-v accines

[18] Farge, E. (2021) Vaccine Nationalism Puts World on Brink of 'Catastrophic Moral Failure': WHO Chief. Reuters.

[19] Baker, H. and Murdoch, I.E. (2008) Can a Public Health Intervention Improve Awareness and Health-Seeking Behaviour for Glaucoma? British Journal of Ophthalmology, 92, 1671-1675. https://doi.org/10.1136/bjo.2008.143537

[20] Seymour, J. (2017) The Impact of Public Health Awareness Campaigns on the Awareness and Quality of Palliative Care. Journal of Palliative Medicine, 20, S30-S36.

https://doi.org/10.1089/jpm.2017.0391

[21] World Americas (2021) COVID-19: Vaccine Rollout Hits Snag in US as Health Workers Balk at Shots.

https://gulfnews.com/world/americas/covid-19-vaccine-rollout-hits-snag-in-us-as-h ealth-workers-balk-at-shots-1.1610173961760

[22] The News (2021) Dubai Restaurants Announce Exciting Incentive for Vaccinating against COVID-19.

https://www.thenews.com.pk/latest/779616-dubai-restaurants-announce-exciting-in centive-for-vaccinating-against-covid-19 
[23] Seth, R., et al. (2018) Mobile Phone Incentives for Childhood Immunizations in Rural India. Pediatrics, 141, e20173455. https://doi.org/10.1542/peds.2017-3455

[24] AP News (2020) Can Employers Make COVID-19 Vaccination Mandatory? https://apnews.com/article/can-employers-covid-19-vaccine-mandatory-ba22c99f01 f24ea3be7631ff751f0d 82

[25] Fujiwara, S. (2006) Is Mandatory Vaccination Legal in Time of Epidemic? AMA Journal of Ethics, 8, 227-229. https://doi.org/10.1001/virtualmentor.2006.8.4.hlaw1-0604

[26] Savulescu, J. (2021) Good Reasons to Vaccinate: Mandatory or Payment for Risk? Journal of Medical Ethics, 47, 78-85. https://doi.org/10.1136/medethics-2020-106821

[27] Hassan, Z., Sa'id, A.S. and Mohammed, H.A. (2021) Is Distance E-Learning Option Acceptable by Nigerians amidst COVID-19 Pandemic? African Journal of Education and Practice, 7, 11-25.

[28] CDC (2020) COVID-19 and Your Health. Centers for Disease Control and Prevention. https://www.cdc.gov/coronavirus/2019-ncov/vaccines/recommendations.html

[29] NHS (2020) Coronavirus (COVID-19) Vaccine. NHS Website. https://www.nhs.uk/conditions/coronavirus-covid-19/coronavirus-vaccination/coro navirus-vaccine/

[30] Weintraub, R. and Mohta, N.S. (2021) Covid-19 Vaccine Distribution: One of the Most Complex Tasks in American Public Health History. NEJM Catalyst.

[31] DoH Louisiana (2021) Louisiana Joins Federal Retail Pharmacy Program to Expand COVID Vaccine Distribution. Department of Health, State of Louisiana. https://ldh.la.gov/index.cfm/newsroom/detail/6011

[32] Estrin, D. (2021) Vaccines for Data: Israel's Pfizer Deal Drives Quick Rollout-And Privacy Worries. NPR. https://www.npr.org/2021/01/31/960819083/vaccines-for-data-israels-pfizer-deal-dr ives-quick-rollout-and-privacy-worries

[33] Barrett, A.D.T. (2016) Vaccinology in the Twenty-First Century. npj Vaccines, 1, Article No. 16009. https://doi.org/10.1038/npjvaccines.2016.9

[34] Bangura, J.B., Xiao, S.Y., Qiu, D., Ouyang, F.Y. and Chen, L. (2020) Barriers to Childhood Immunization in Sub-Saharan Africa: A Systematic Review. BMC Public Health, 20, Article No. 1108. https://doi.org/10.1186/s12889-020-09169-4

[35] Pollard, A.J. and Bijker, E.M. (2020) A Guide to Vaccinology: From Basic Principles to New Developments. Nature Reviews Immunology, 21, 83-100.

[36] WHO (2021) Raising Awareness of Immunization. https://www.who.int/westernpacific/activities/raising-awareness-of-immunization

[37] Henao-Restrepo, A.M., et al. (2015) Efficacy and Effectiveness of an rVSV-Vectored Vaccine Expressing Ebola Surface Glycoprotein: Interim Results from the Guinea Ring Vaccination Cluster-Randomised Trial. The Lancet, 386, 857-866. https://doi.org/10.1016/S0140-6736(15)61117-5

[38] Kanapathipillai, R., et al. (2014) Ebola Vaccine-An Urgent International Priority. The New England Journal of Medicine, 371, 2249-2251. https://www.nejm.org/doi/10.1056/NEJMp1412166

[39] Lurie, N., Saville, M., Hatchett, R. and Halton, J. (2020) Developing Covid-19 Vaccines at Pandemic Speed. New England Journal of Medicine, 382, 1969-1973. https://doi.org/10.1056/NEJMp2005630

[40] Jeyanathan, M., Afkhami, S., Smaill, F., Miller, M.S., Lichty, B.D. and Xing, Z. (2020) Immunological Considerations for COVID-19 Vaccine Strategies. Nature Reviews 
Immunology, 20, 615-632. https://doi.org/10.1038/s41577-020-00434-6

[41] Geddes, L. (2021) Who Can't Have a COVID-19 Vaccine? Gavi. https://www.gavi.org/vaccineswork/who-cant-have-covid-19-vaccine

[42] CDC (2020) COVID-19 Vaccination. Centers for Disease Control and Prevention. https://www.cdc.gov/coronavirus/2019-ncov/vaccines/recommendations/older-adul ts.html

[43] Lazarus, J.V., et al. (2021) A Global Survey of Potential Acceptance of a COVID-19 Vaccine. Nature Medicine, 27, 225-228. https://doi.org/10.1038/s41591-020-1124-9

[44] Al-Qerem, W.A. and Jarab, A.S. (2021) COVID-19 Vaccination Acceptance and Its Associated Factors among a Middle Eastern Population. Frontiers in Public Health, 9, Article ID: 632914. https://doi.org/10.3389/fpubh.2021.632914

[45] WHO (2020) Coronavirus Disease (COVID-19): Herd Immunity, Lockdowns and COVID-19.

https://www.who.int/news-room/q-a-detail/herd-immunity-lockdowns-and-covid19

[46] NPHCDA (2021) COVID-19 Vaccination Update for May 6th 2021, in 36 States+ the FCT. Is Your State Still Vaccinating? \#YesToCOVID19Vaccine. https://twitter.com/NphcdaNG/status/1390560529018724352

[47] McMillan, A. (2021) Mandatory Vaccination: Legal, Justified, Effective? IBA. https://www.ibanet.org/Article/NewDetail.aspx?ArticleUid=70e1f93e-a23b-4f1a-a59 6-aeef84750241

[48] Gravagna, K., et al. (2020) Global Assessment of National Mandatory Vaccination Policies and Consequences of Non-Compliance. Vaccine, 38, 7865-7873. https://doi.org/10.1016/j.vaccine.2020.09.063

[49] Al Amir, K. (2021) Saudi Arabia: Vaccination required to Perform Umrah. World Gulf. https://gulfnews.com/world/gulf/saudi/saudi-arabia-vaccination-required-to-perfor m-umrah-1.78350195

[50] Hassan, R. (2021) Saudi Arabia: Vaccine Required to Enter Prophet's Mosque, Permit Needed for Umrah. Arab News. https://arab.news/pb9re

[51] Fisher, K.A., Bloomstone, S.J., Walder, J., Crawford, S., Fouayzi, H. and Mazor, K.M. (2020) Attitudes toward a Potential SARS-CoV-2 Vaccine: A Survey of U.S. Adults. Annals of Internal Medicine, 173, 964-973. https://doi.org/10.7326/M20-3569

[52] Neumann-Böhme, S., et al. (2020) Once we Have It, Will We Use It? A European Survey on Willingness to be Vaccinated against COVID-19. The European Journal of Health Economics, 21, 977-982. https://doi.org/10.1007/s10198-020-01208-6

[53] Wang, J., et al. (2020) Acceptance of COVID-19 Vaccination during the COVID-19 Pandemic in China. Vaccines, 8, Article No. 482.

https://doi.org/10.3390/vaccines 8030482

[54] Moore, T. (2021) COVID-19 Vaccine Blood Clot Fears: Under-40s to Be Offered Alternative to AstraZeneca Jab as Advice Changes. Sky News.

https://news.sky.com/story/under-40s-to-be-offered-alternative-to-oxford-jab-overblood-clot-fears-12299219

[55] Pinho, A.C. (2021) AstraZeneca's COVID-19 Vaccine: EMA Finds Possible Link to Very Rare Cases of Unusual Blood Clots with Low Platelets. European Medicines Agency.

https://www.ema.europa.eu/en/news/astrazenecas-covid-19-vaccine-ema-finds-poss ible-link-very-rare-cases-unusual-blood-clots-low-blood 
[56] Mahase, E. (2021) Covid-19: AstraZeneca Vaccine Is Not Linked to Increased Risk of Blood Clots, Finds European Medicine Agency. British Medical Journal, 372, n774. https://doi.org/10.1136/bmj.n774

[57] WHO (2021) Interim Recommendations for Use of the ChAdOx1-S [Recombinant] Vaccine against COVID-19 (AstraZeneca COVID-19 Vaccine AZD1222, SII COVISHIELD, SK Bioscience).

https://www.who.int/publications-detail-redirect/WHO-2019-nCoV-vaccines-SAG E recommendation-AZD1222-2021.1

[58] Lucero-Prisno, D.E., Ogunkola, I.O., Imo, U.F. and Adebisi, Y.A. (2021) Who Will Pay for the COVID-19 Vaccines for Africa? The American Journal of Tropical Medicine and Hygiene, 104, 794-796. https://doi.org/10.4269/ajtmh.20-1506

[59] World Bank (2020) World Bank Approves \$12 Billion for COVID-19 Vaccines. https://www.worldbank.org/en/news/press-release/2020/10/13/world-bank-approve s-12-billion-for-covid-19-vaccines 


\section{Supplementary}

Questionnaire for the study: Assessment of COVID-19 Vaccine Acceptance and Willingness to Pay by Nigerians

\section{Section A: Demographic Information}

1) Gender

Male [ ] Female [ ]

2) Age ---------------------

3) Nationality

4) Country of residence

5) State of origin

6) Marital status

Single [ ] Married [ ] Divorced [ ] Separated [ ] Widowed [ ]

Cohabiting [ ]

Others -----------

7) Level of Education

Primary [ ] Secondary [ ] Tertiary [ ] Others -------------

8) Occupation

Civil Servant [ ] Businessman/woman [ ] Student [ ]

Employee at private firm [ ] Unemployed [ ] Others -----------

Section B: Awareness and willingness to accept COVID-19 vaccination

1) Do you think COVID-19 vaccine can stop the spread of COVID-19?
Yes [ ]
No [ ]
Don't know [ ]

2) Do you think COVID-19 vaccine is safe?
Yes [ ]
No [ ]
Don't know [ ]

3) Will you take COVID-19 vaccine if given for free?

Yes [ ] No [ ] Don't know [ ]

4) Will you allow your family members take COVID-19 vaccine?

Yes [ ] No [ ] Don't know [ ]

5) Will you pay for COVID-19 vaccine if not given free?
Yes [ ]
No [ ]
Don't know [ ]

6) Are you likely to take COVID-19 vaccine if government provides some incentives?
Yes [ ]
No [ ]
Don't know [ ]

7) I will only take COVID-19 vaccine if government makes it compulsory
Yes [ ]
No [ ]
Don't know [ ]

8) Do you know any accredited COVID-19 test laboratory?

Yes [ ] No [ ]

9) Have you been tested for COVID-19?

Yes [ ] No [ ]

10) Have you or anyone you know tested POSITIVE for COVID-19?

Yes [ ] No [ ]

11) Do you know anyone who died as a result of COVID-19 complications?

$$
\text { Yes [ ] No [ ] }
$$

